\title{
1D and 3D Modeling of Modern Automotive Exhaust Manifold
}

\author{
B. Mohamad ${ }^{1 *}$, A. Zelentsov ${ }^{2}$
}

${ }^{1}$ Faculty of Mechanical Engineering and Informatics, University of Miskolc-3515 MiskolcHungary e-mail: pywand@gmail.com

${ }^{2}$ Piston Engine Department, Bauman Moscow State Technical University, 105005 MoscowRussia

e-mail: Zelentsov.aa@gmail.com

*corresponding author

\begin{abstract}
This paper presents the simulation of the multi-cylinder 4-stroke cycle spark-ignition engine using a commercial simulation tool, AVL BOOST and Fire. Various models were examined to select the appropriate models that would best serve to analyze the main components of the exhaust systems: the plenum chamber, the muffler and the exhaust manifold branch junction. For the plenum chamber and the muffler, the whole duct model was tested. In order to analyze the exhaust manifold branch junction, a complicated model which reflects the actual shape and involves pressure drops, velocity magnitude and sound pressure was compared to a simplified one. However, the results from 1D and 3D model calculations compared with Honda K20B Engine experimental data also show that both models are applicable with satisfying accuracy for exhaust manifold branch junction. The simplified 1D model is recommended in regard to convenience in modeling and efficiency in calculation.
\end{abstract}

Keywords: Internal combustion engine, exhaust system, sound level, computational fluid dynamics, engine modeling.

\section{Introduction}

Simulation of flow in exhaust manifold can be done to provide solutions of engineering problems and for optimization purposes. Manifold is a first part of exhaust system that can be classified into two types of inlet and outlet manifolds or manifolds of air and exhaust gases. The duty of the exhaust manifold (EM) is to direct the smoke and emit the hot smoke from the combustion of the fuel, while the air or intake manifold (IM) is responsible for directing the mixture of air and fuel into the combustion chamber. Although the tasks are simple, there are a lot of subtlety and delicacy in performing these tasks. The design of the manifold in internal combustion engines has always been the interest of the researchers and designers of these engines. As more than a century has passed since the invention of the first prototype of these engines, we still have a lot of researches in this field, for instance the design and optimization of the manifold (Mohiuddin et al. 2008). The manifold in the internal combustion engine plays the role of the respiratory 
system of the engine, and its proper design results in an increase in engine efficiency, power, torque, and its effects on fuel consumption and pollutant production. Mohamad et al. (2017) used 1D AVL-Boost software to describe the effect of using different kinds of blend fuels on engine performance and exhaust properties. The results show variation of outlet temperature and emission gas characteristics for $\mathrm{CO}, \mathrm{NOx}$, and $\mathrm{CO} 2$ by using different volume percentage of alcohol-gasoline blends. Mohamad et al. (2018) studied the effect of Ethanol-Gasoline blend fuel on engine power output and emissions. Literature results show great improvement in combustion process and exhaust gas characteristics. Mohamad et al. (2017) presented in their paper the review of muffler used in industry, and this review depicts flow and temperature distribution along the muffler ducts. The techniques for different methods used in the design, calculation and construction of muffler both experimentally, practically and transmission loss characteristics were described. Heat flow and mixing were well predicted by this CFD (computational fluid dynamics) study and based on analysis data the amount of heat that can be recovered is found out.

The objective of this research is to predict pressure and flow distribution inside the manifold and then studied for heat transfer between exhaust gases and the acoustics energy that generated along this part.

\section{Software modeling}

AVL-Suite is the industry-standard engine simulation tool, used by all leading engine and vehicle manufacturers and their suppliers. It is also used for ship and power-generation engines, two and four stroke engines and racing engines. It provides the user with many components to model any advanced concept, also provides many advanced capabilities in the area of acoustic modeling, according to Vishal and Hujare (2014), (Rogerio 2013):

- Microphone model for predicting noise radiated from intake/exhaust opening

- Intuitive, 3D CAD based preprocessor for importing, cleaning, and meshing

- Complex geometries found in mufflers, molded air boxes, and irregular plenums

- Fast, linear analysis for rapid concept evaluation, standard nonlinear analysis for final concept validation

- Advanced post-processing for easy creation of Campbell diagrams, order cuts, etc.

Based on proto-type virtual standard (Honda K20B) engine used to test the EM performance and their effects on engine power (Fig.1). 


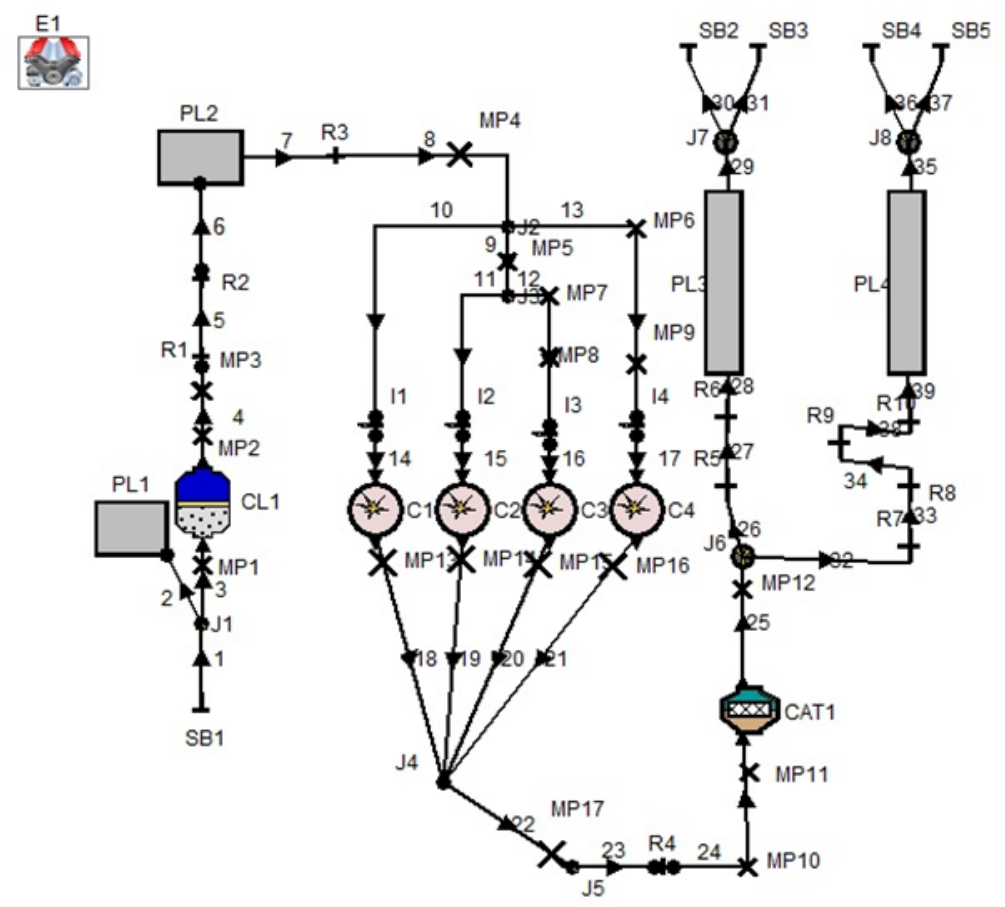

Fig. 1. Engine diagram of base model of Honda K20B, the diagram constructed by $1 D$ AVL Boost

The term 1D model implies a one-dimensional approach to the description of processes in the intake and exhaust systems of the piston engine. The one-dimensional statement of the problem allows estimating the influence of pipelines and channels dimensions (diameters, lengths, fillet radii) on the gas flow.

At the same time, despite the name "one-dimensional model", the processes inside the cylinder are considered in the zero-dimensional formulation. With this approach, the entire cylinder (section) is considered as a single volume in which the processes of intake, compression, combustion, expansion and outlet occur. This volume, unlike the three-dimensional approach, is not divided into subdomains (control or finite volumes). The system of equations (energy, continuity, gas state) is written only for one volume that changes with time (in the threedimensional approach - the system of equations is solved for each control volume).

It is more correct to call this approach zero-one-dimensional, but the term $1 \mathrm{D}$ approach is more common, and it was used to refer to the model created in AVL Boost. The 3D model of base EM was sketched based on specific prototype engine using advanced design software CATIA V5, including four inlet ducts, connected to outlet plenum. The 3D base model of EM is presented (Fig. 2). In this analysis, simulation of flow in manifold has been done by 1D AVL Boost software then by 3D CFD tools-AVL Fire software. 


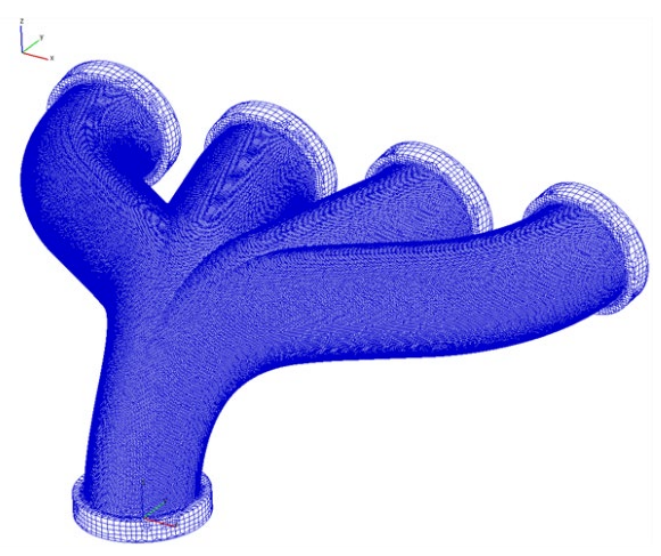

Fig. 2. 3D Model of base model of EM constructed by 3D AVL Fire

Presently, there are different software products that can provide this kind of calculation. Recent advances in modeling and accurate performance prediction has led to the use of simulation methods for manifold performance calculation in commercial design. 1D AVL-Boost software was coupled with 3D Fire which is based on finite volume analysis, the engine diagram and the calculation were done.

\begin{tabular}{|l|l|}
\hline Engine type & In-line \\
\hline Engine displacement & $1.9981 \mathrm{~cm}^{3}$ \\
\hline Bore & $86 \mathrm{~mm}$ \\
\hline Stroke & $86 \mathrm{~mm}$ \\
\hline Number of cylinders & 4 \\
\hline Con. rod. length & $143.5 \mathrm{~mm}$ \\
\hline Compression ratio & 10.5 \\
\hline Engine speed & $2000-5000 \mathrm{rpm}$ \\
\hline
\end{tabular}

Table 1. Engine parameters

After evaluation of base EM the results of pressure output, mass flow rate and power from the engine model were monitored for optimization purpose. Another modified EM was constructed to increase the power output of the standard engine (Fig. 3). 


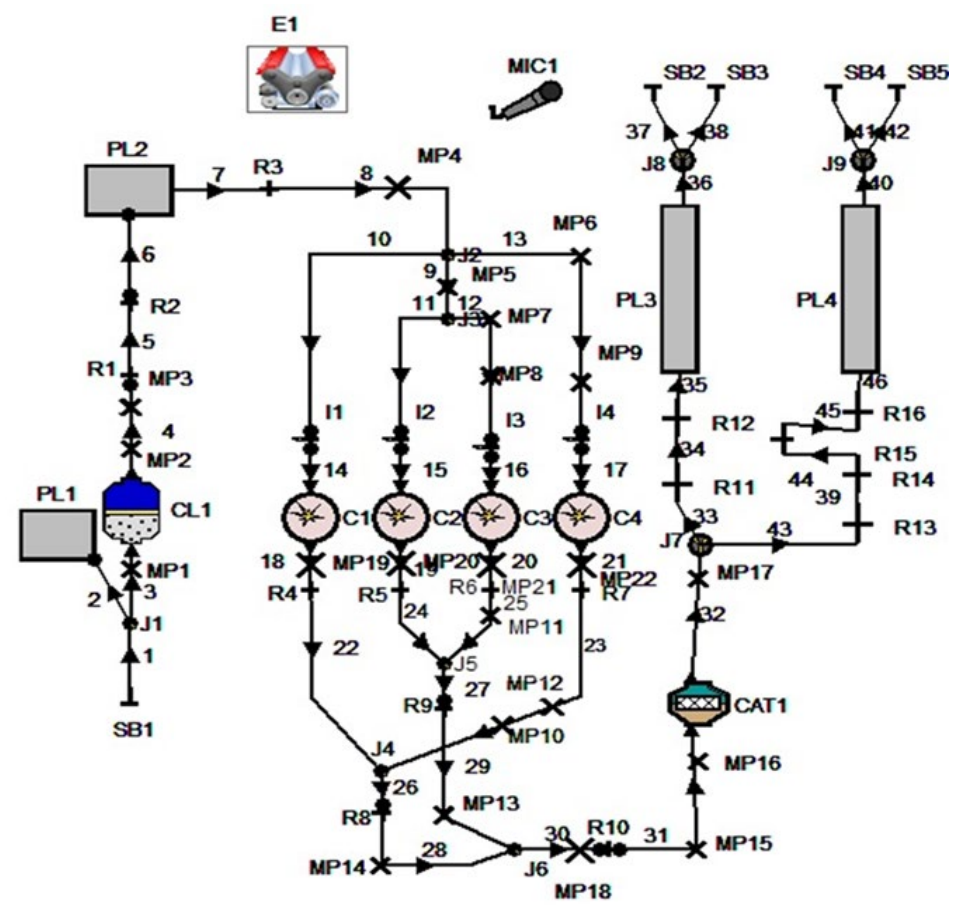

Fig 3. Modified engine diagram of base model of Honda K20B, the diagram constructed by 1D AVL Boost

In acoustics simulation phase, first 3D CAD model is converted into the 1D model by using AVLSuite software and 1D model is prepared for the simulation.

\begin{tabular}{|l|l|}
\hline Type of model & 3D \\
\hline Type of mesh & Mapped \\
\hline Total number of elements & 1394935 \\
\hline Volume of model & $0.00130 \mathrm{~m}^{3}$ \\
\hline Surface area & $0.1122 \mathrm{~m}^{2}$ \\
\hline
\end{tabular}

Table 2. Model properties

Acoustics simulation has been done for the different order of the engines like $2^{\text {nd }}$ and $4^{\text {th }}$ order and as well for the low frequency and high frequency. 3D model used for the simulation purposes is provided in the STL format for the preparation of the 1D model and to build it for the execution.

\begin{tabular}{|l|l|}
\hline Type of model & 3D \\
\hline Type of mesh & Mapped \\
\hline Total number of elements & 534715 \\
\hline Volume of model & $0.00414 \mathrm{~m}^{3}$ \\
\hline Surface area & $0.3546 \mathrm{~m}^{2}$ \\
\hline
\end{tabular}

Table 3. Modified model properties 
The mesh was generated to modified EM for 3D calculation based on finite volume method, the pressure and velocity for the gas in ducts were monitored (Fig. 4).

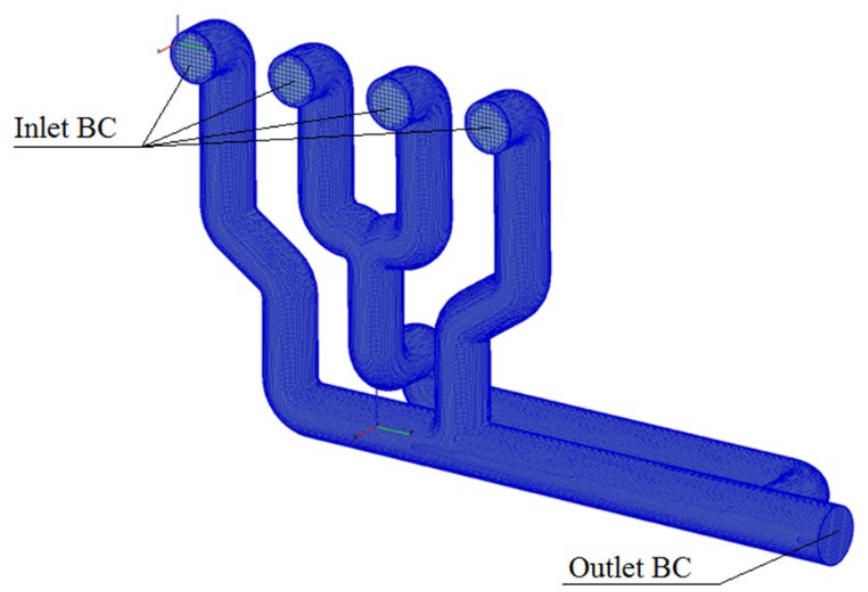

Fig. 4. 3D model of modified of EM after applying mesh constructed by 3D AVL Fire

Inlet boundary conditions (BC) were mass flow and temperature values from measuring points MP 19, 20, 21, 22 (Fig. 3), outlet BC - pressure in MP 18. In addition, the internal surface temperatures of the exhaust manifold were set on the walls: $\mathrm{Tw}=850 \mathrm{~K}$.

The initial conditions were the temperature and pressure inside the calculated volume at the initial moment of calculation (the data were taken from the calculation results in Boost).

The pressure drop was defined as the difference between the pressure in the exhaust manifold at the cylinder outlet and the cross section at the outlet of the computational volume.

\section{Mathematical model}

The mathematical model is based on the fundamental equations of three-dimensional nonstationary transport: the equations of momentum (Navier-Stokes), energy (Fourier-Kirchhoff) and the conservation of mass (continuity), which take the form of Reynolds after the averaging procedure by the Favre method:

$$
\begin{aligned}
& \bar{\rho} \frac{D \overline{W_{l}}}{D \tau}=\overline{G_{l}}-\frac{\partial \bar{p}}{\partial x_{i}}+\frac{\partial}{\partial x_{j}}\left[\mu\left(\frac{\partial \overline{W_{l}}}{\partial x_{j}}+\frac{\partial \overline{W_{J}}}{\partial x_{i}}-\frac{2}{3} \delta_{i j} \frac{\partial \overline{W_{k}}}{\partial x_{k}}\right)-\bar{\rho} \overline{W_{l}^{\prime} W_{J}^{\prime}}\right] \\
& \bar{\rho} \frac{\overline{D H}}{D \tau}=\overline{G_{j} W_{j}}+\frac{\partial \bar{p}}{\partial \tau}+\frac{\partial}{\partial x_{i}}\left(\bar{\tau}_{i j} \overline{W_{j}}\right)+\frac{\partial}{\partial x_{j}}\left(\lambda \frac{\partial \bar{T}}{\partial x_{j}}-c_{p} \bar{\rho} \overline{T^{\prime} W_{j}^{\prime}}\right) \\
& \frac{\partial \bar{\rho}}{\partial \tau}+\frac{\partial}{\partial x_{j}}\left(\overline{\rho W_{j}}\right)=0 .
\end{aligned}
$$

Where $W$ is the velocity, $\mathrm{m} / \mathrm{s} ; p$ is the pressure, $\mathrm{N} / \mathrm{m}^{2} ; G_{i}$ is the projection of the density vector of the volume forces $\left(\mathrm{N} / \mathrm{m}^{3}\right)$ onto the $O x_{i}$ axis of a rectangular Cartesian coordinate system; $H$ is the total specific energy, $\mathrm{J} / \mathrm{kg} ; \mu$ is the dynamic viscosity, $\mathrm{kg} /(\mathrm{m} \mathrm{s}) ; c_{p}$ is the heat capacity at constant 
pressure, $\mathrm{J} /(\mathrm{kg} \cdot \mathrm{K}), \lambda$ is the thermal conductivity, $\mathrm{W} /(\mathrm{m} \mathrm{K}) ; \delta_{i j}$ is the Kronecker symbol; and $\frac{D}{D \tau}$ is the substantial derivative. In equation (1), the Einstein summation rule is used for the twice repeated $i, j$, and $k$ indices.

The system of transport equations in the Reynolds form (1) is closed by the $k-\zeta-f$ model of turbulence specially developed and verified for the processes of flow, combustion, and heat transfer in piston engines (Tatschl et al. 2005; Tatschl et al. 2006). It consists of three equations: for the $k$ kinetic energy of turbulence, for the $\varepsilon$ dissipation rate of this energy known from the $k$ $\varepsilon$ model of turbulence, and the equations for the normalized velocity scale $\zeta=\bar{W}^{2} / k$. The $k-\zeta-f$ turbulence model proposed by Hanjalič et al. (2004) contains the Durbin elliptical function of $f$, which takes into account the near-wall anisotropy of turbulence.

The equations of the system (1) are used to describe, respectively, the flow velocities W (NavierStokes equation), the enthalpy $\mathrm{H}$ (energy equation) and the mass or density (continuity equation) for each control volume of the considered computational domain. Wall heat transfer is determined through the thickness of the boundary layer using hybrid wall function (Popovać and Hanjalić et al. 2005).

We also emphasize that this mathematical model is typical for CFD calculations of processes in piston engines and it is described in detail in Merker et al. 2019; Basshuysen and Schäfer 2007; Kavtaradze et al. 2009).

\section{Results}

The results from 1D and 3D AVL calculations for the engine schemes in both (base and modified) EM. The pressure output from the base engine was compared with modified scheme at complete engine cycles as show in Fig. 5.

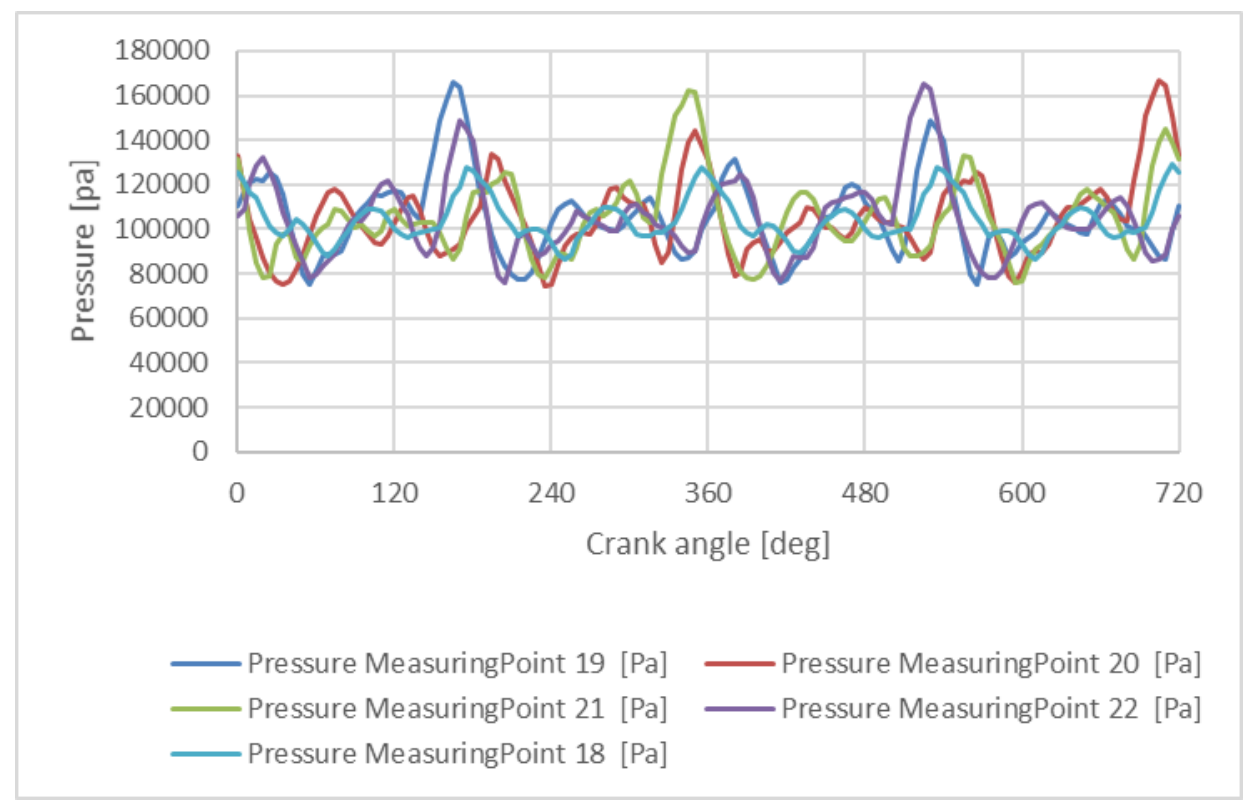

Fig. 5. Pressure outlet from the engine scheme with base EM at $2000 \mathrm{rpm}$ 
The average pressure in exhaust system during the exhaust stroke is called mean exhaust pressure and the atmospheric pressure is called the ambient pressure. The difference between these two pressures is defined as back pressure (Figs. 6 and 8). Several junctions or joiner were made to new geometry to reduce backflow as much as possible. The channel extension in downstream was made better tuning for flow path.

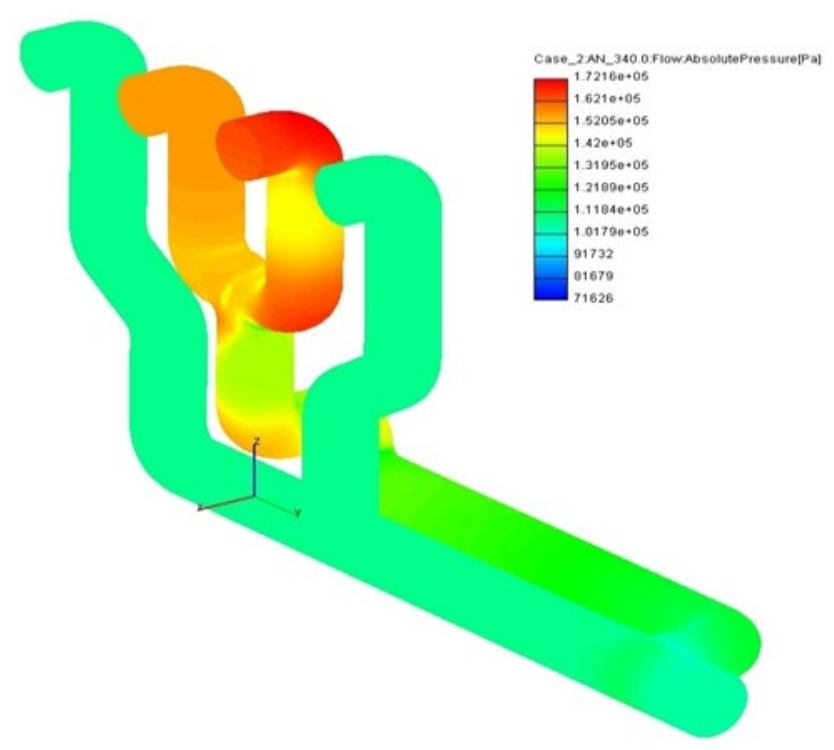

Fig. 6. Pressure distribution at measuring point 22 from new engine scheme

The computed pressured drop in Fig. 6 is in a fair agreement with the 1D results (Fig. 8) for the case with modified EM.

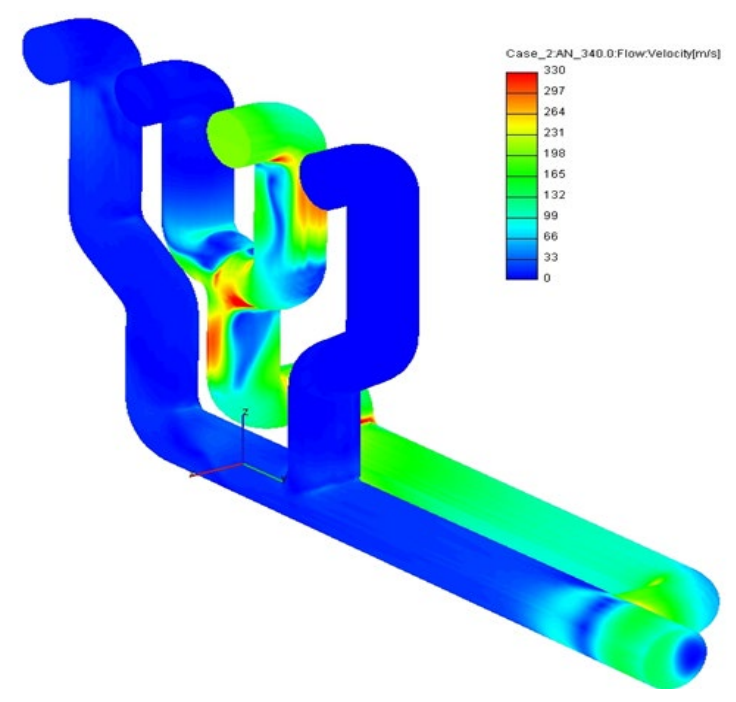

Fig 7. Flow direction expressed by vectors (Modified- EM) Velocity 


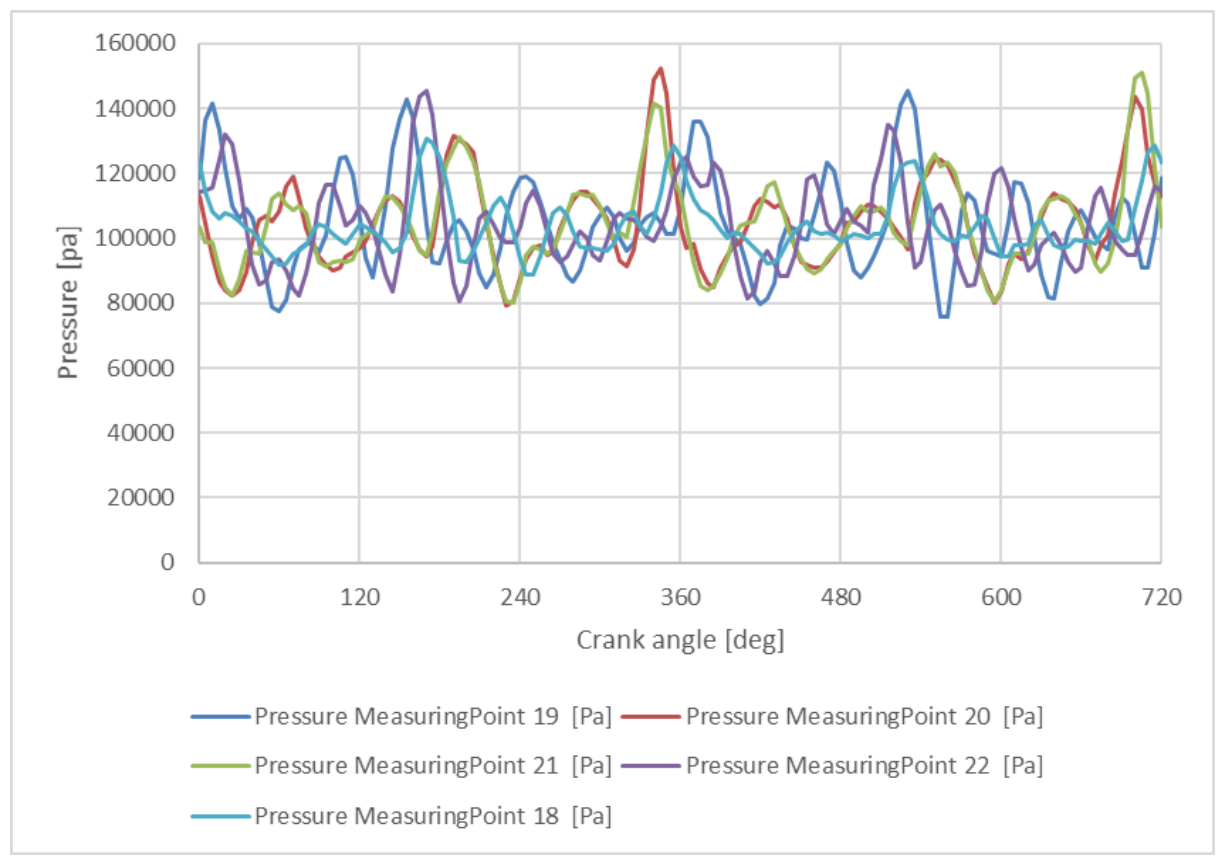

Fig. 8. Pressure outlet from the engine scheme with modified EM at $2000 \mathrm{rpm}$

The sound pressure level (SPL) records higher value in base EM, and smother in modified EM at same engine speed. The average engine speed (2000-5000) rpm would create the best operating condition of this manifold design (Fig. 9).

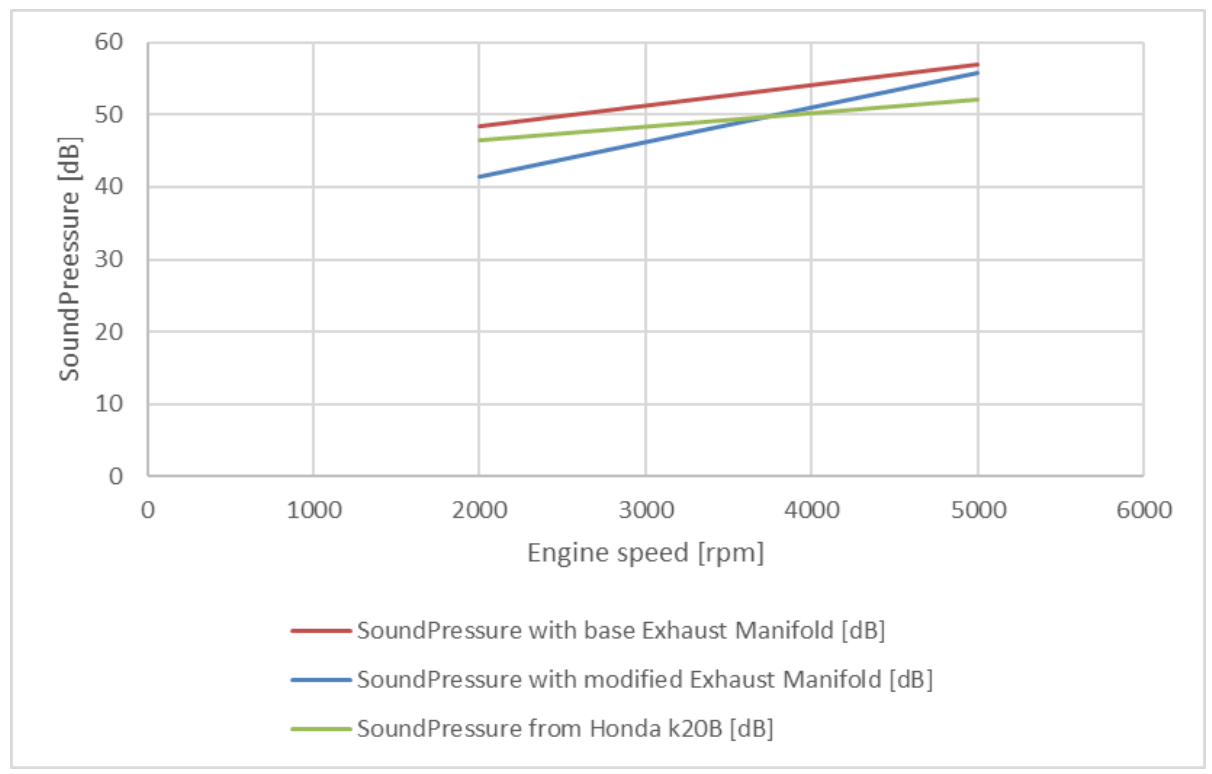

Fig. 9. Comparison sound pressure level for base, modified EM and Honda data at different engine speed 
It is understood that the design of the manifold must meet certain requirement set by the countries where the car is going to be marketed. The parameters that govern the performance of the manifold are manifold design, restrictions of the flow of the exhaust gas, so the mass flow rate and power output from the engine scheme for both (base, modified) EM were monitored.

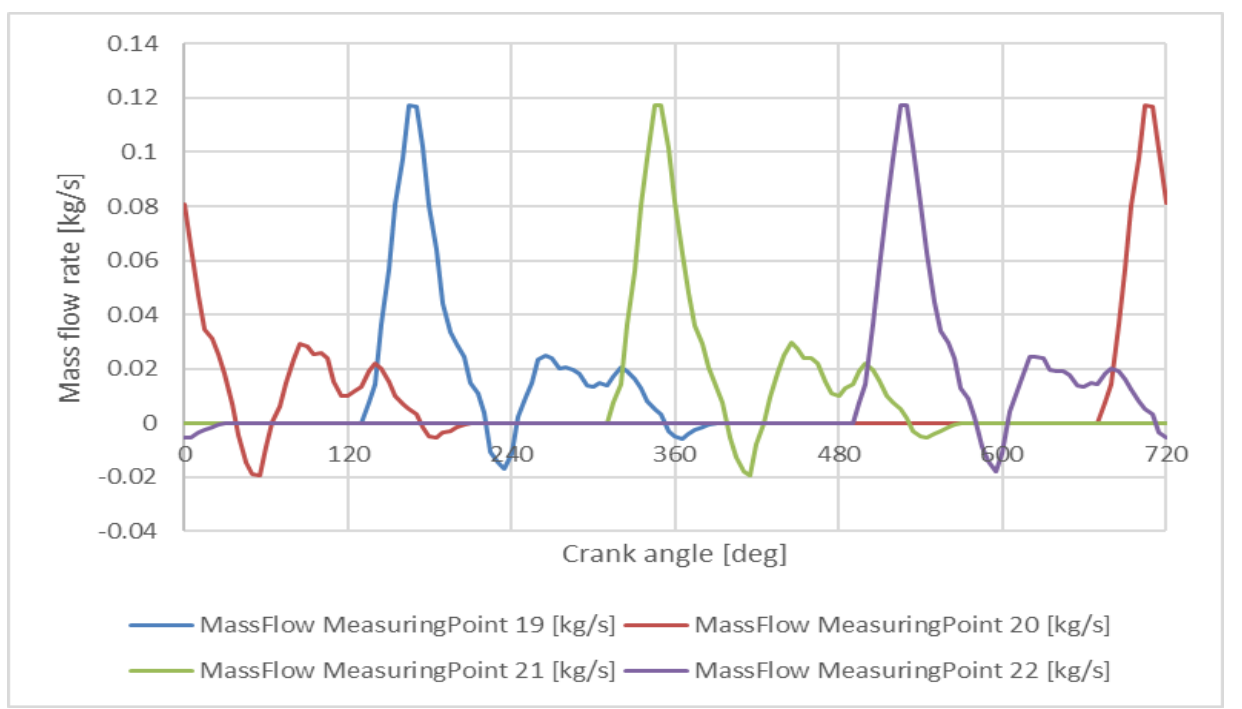

Fig. 10. Mass flowrate of exhaust gas through base manifold channels for complete cycle at $2000 \mathrm{rpm}$

The exhaust flow oscillation at selected rpm is high and significant amount of backward flow is observed for both models (Figs. 11-12).

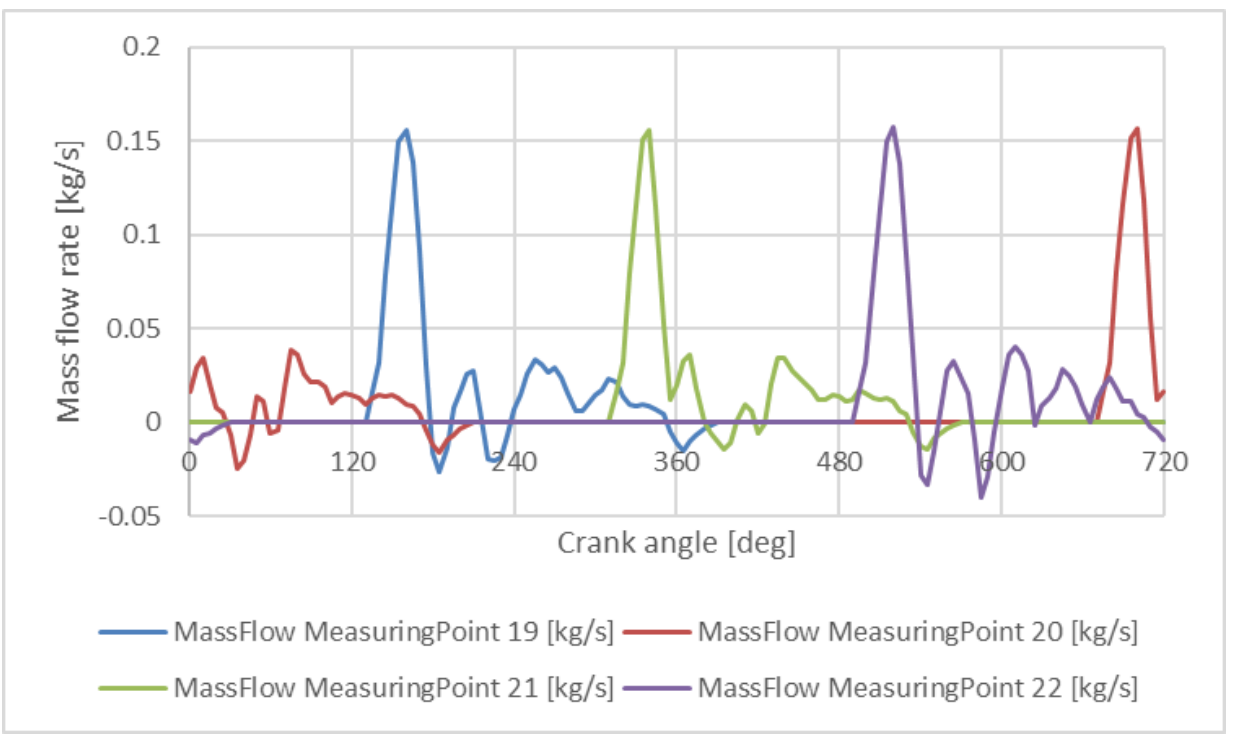

Fig. 11. Mass flowrate of exhaust gas through modified manifold channels for complete cycle at $2000 \mathrm{rpm}$ 
The change in the variants of power output is closely related to the exhaust gas path design. The higher back pressure created by exhaust system, the less net power is available on the crankshaft. The amount of the power loss depends on many factors, but a good rule is that one with new flow path position (Fig. 12).

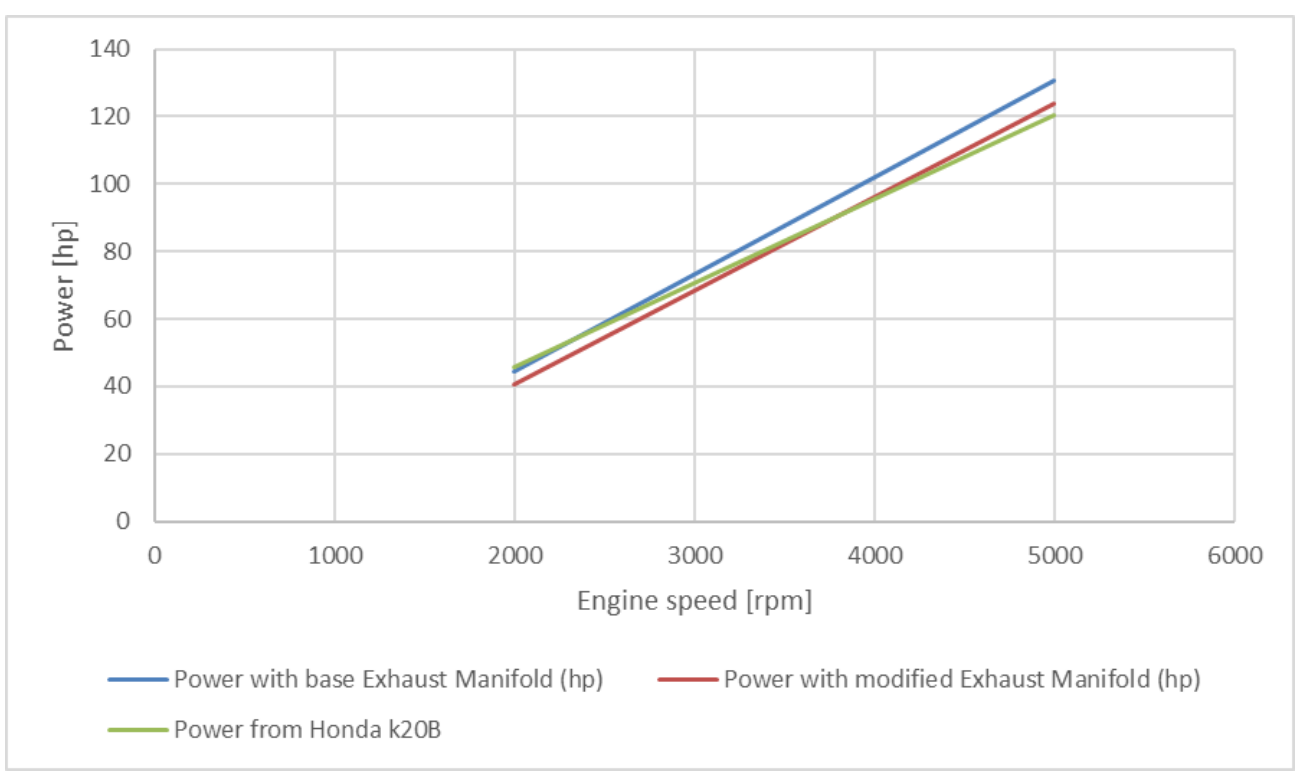

Fig. 12. Comparison of Power output [hp] from the engine scheme for both EM and Honda data

\section{Conclusions}

This paper presents new simulation models for flow and regeneration in a gasoline engine manifold. The models have been implemented into the 1D code BOOST and into the 3D code FIRE. A workflow is designed which makes it possible to automatically determine the necessary model parameters and to use them in both 1D and 3D simulations. The comparison with experimental results from Honda K20B engine data was done and show that the model accurately captures the relevant effects. Results of a 3D simulation of an exhaust gas line are presented (Fig. 6-7). The same procedure can be carried out for each unit that is part of the exhaust gas line. The optimization was done to the manifold part of exhaust system which boost the efficiency of engine power $5 \%$ at $2000-4000 \mathrm{rpm}$ due to proper gas ducting with respect to piston motion.

\section{References}

Basshuysen R, Schäfer, F (2007). Hrsg. Handbuch Verbrennungsmotor. 4. Auflage. Vieweg und Sohn Verlag. Wiesbaden. 1032.

Kavtaradze R Z, Onishchenko D O, Zelentsov A A, Sergeev S S (2009). The influence of rotational charge motion intensity on nitric oxide formation in gas-engine cylinder. International Journal of Heat and Mass Transfer. 52.

Merker G, Schwarz Ch, Teichmann R (2019). Grundlagen Verbrennungsmotoren: Funktionsweise, Simulation, Messtechnik (Fundamentals of Internal Combustion Engines: Mode of Operation, Simulation, Measurement Technology), 9th ed, Springer, Wiesbaden. 1117. 
Mohamad B, Szepesi G, Bolló B, (2017). Combustion Optimization in Spark Ignition Engines. Multi-Science - XXXI. microCAD Scientific Conference, University of Miskolc, Hungary.

Mohamad B, Szepesi G, Bolló B (2018). Review Article: Effect of Ethanol-Gasoline Fuel Blends on the Exhaust Emissions and Characteristics of SI Engines. Lecture Notes in Mechanical Engineering. 29-41.

Mohamad B, Szepesi G, Bolló B (2017). Review Article: Modelling and Analysis of a Gasoline Engine Exhaust Gas Systems. International Scientific Conference on Advances in Mechanical Engineering, University of Debrecen, Hungary.

Mohiuddin A., Mohd Rashidin Ideres, Shukri Mohd Hashim (2008). Experimental Analysis of Noise and Back Pressure for Muffler Design. Journal Kejuruteraan. 20: 10.17576/jkukm.

Popovać, M, Hanjalić, K (2005). Compound Wall Treatment for RANS Computation of Complex Turbulent Flow. Proc. 3rd M.I.T. Conference, Boston, USA.

Rogerio Gonçalves dos Santos, Cavaglieri, M R, Thomas M M, (2013). An Experimental Approach for Intake Manifold Tuning for Internal Combustion Engines. 22nd International Congress of Mechanical Engineering, Ribeirão Preto, SP, Brazil.

Tatschl R, Basara B, Schneider J, Hanjalic K, Popovac M, Brohmer A, Mehring J, (2006). Advanced Turbulent Heat Transfer Modeling for IC-Engine Applications Using AVL FIRE. Proceedings of International Multidimensional Engine Modeling User's Group Meeting. Detroit, USA.

Tatschl R, Schneider J, Basara D, Brohmer A, Mehring A, Hanjalić K, (2005). Progress in the 3D-CFD calculation of the gas and water side heat transfer in engines. in Verfahren 10 Tagung der Arbeitsprozess des Verbrennungsmotors (Proc. 10th Meeting on the Working Process of the Internal Combustion Engine), Graz, Austria.

Technical Information RSX VTEC and VTC. Hondata. Retrieved from https://www.hondata.com. 21 April 2018.

Vishal Vaidya, Hujare P P (2014). Optimization of Sound Pressure Level of Air Intake System by using GT-Power. International Journal of Emerging Science and Engineering, (8) 2. 